\title{
Inheritance and Industrial Development of Traditional Handcraft Paper Making Process in Beizhang Village, Chang'an Shaanxi
}

\author{
Yuan Shao \\ School of Fine Arts \\ Shaanxi Normal University \\ Xi' an, China
}

\begin{abstract}
China's paper making technique has been leading around the world, which has witnessed the development of over two-thousand years since Han and Tang dynasties. The handcraft paper making process in Beizhang Village, Changan, Shaanxi, a remains of the ancient paper making, is in a trend of being forgotten during the evolvement of historic culture and economic development. For the intangible cultural heritages which are gradually disappearing in China, the optimal method to inherit is to industrialize. Based on the status quo and paper making process in Beizhang Village, the article compares the paper making industries between the region and other regions in the country and raises feasible suggestions for the industrialization of handcraft paper making in Shaanxi. The industrialized development is expected to improve the understanding of the public to the handcraft paper making, expand the publicity and increase the economic benefits so as to continue the handcraft paper making process in Beizhang Village, Changan.
\end{abstract}

Keywords-paper making in Beizhang Village; intangible cultural heritages; inherit; industrialized development

\section{INTRODUCTION}

Since ancient times, paper is a great carrier which reserves the development of human's thoughts around the world as well as the culture and communication of different ethnic groups in all regions, which cannot be achieved by any other civilization. Generally, it is thought by the academic field that all kinds of fibers suspended in water will be taken out of the water with fine screens to filter water, then remove the fiber on the screen and dry, the paper will come into being. Main materials for paper making include bast plants such as hemp, jute, ramie, vine; bark such as mulberry bark; grass family such as bamboo, reed, straws of rice and wheat; as well as seed plant such as cotton. ${ }^{1}$

Paper is widely used, it can be used not only for writing, but also in all aspects such clothing, food, accommodation and travel. After the paper making technology was invented by China, from 2 nd century to 19th century, it was

\footnotetext{
1 Qian Cunxun, History of Chinese and Printing Culture, Guangxi University Press, May 2004 p2.
}

transmitted to other countries in Asia, Africa, Europe and America, reaching every corner around the world.

\section{PAPER MAKING IN BeIZHANG VILlage, ChANG’AN}

\section{A. Historic Source of Paper Making in Beizhang Village}

North regions are sources of handcraft paper making in China, which were cores of paper making in history and replaced by south regions in Song and Yuan dynasties. Beizhang Village, Chang'an District, Xi'an, Shaanxi Province is located at Xinglong Town, Chang'an District, at the foot of Qinling Mountains. The paper making records in Beizhang Village can be traced back to East Han Dynasty, which can be seen from the remains of Baqiao paper, till now, there is a ballad about paper making by Cai Lun spreading in Beizhang Village. In Tang Dynasty, due to the great demand, the paper making workshops in Beizhang Village had their scales enlarged gradually, reaching a peak time. Afterward, the paper making had been serving the palace and the society till the reform and opening up. In Qin Dynasty, it was recorded in Annuals of Chang'an County that the paper made by Beizhang Village was ever used as memorial to the throne and examination paper. Before liberation, the ancient paper made by Beizhang Village was used for packaging and newspaper at Yan'an. After liberation, the paper making process was still flourishing and a temple fair was held on Dec 30 each year at Cai Lun Temple in the village. During the period of people's commune, paper making could be found at almost all families in Beizhang Village, up to now there is still a ballad "characters were developed at Cangjie, tilts were made at Leigong, paper was made at Fengchu", "Women in Beizhang Village had to get up early to work at midnight". After the reform and opening up, due to the poor process and lower economic benefits, the demand for handcraft paper decreased sharply, and lot of young people have given up the traditional handcraft industry and turned to other industries, especially the death of some folk artisans also takes the paper making process away, and handcraft paper making workshops and process are disappearing. 


\section{B. Status Quo of Paper Making in Beizhang Village}

Till now, there are less than ten families which insist on the traditional paper making in the village, yet most are recycled paper, only two or three still inherit ancient methods for paper making. Most of the workers at workshops are old people such as Zhang Fengxue, successor of national intangible cultural heritage, and his son Zhang Jianchang and Ma Zhanding and so on. Before and after houses of villagers, paper making tools can be found rejected here and there, which reflect the flourishing of paper making in old days and also show the embarrassment of current days, main reasons for the situation are given as follows:

1) Modern industrialization has caused the dying of traditional cultural heritage

Nowadays, the social cultural and economic development have greatly lowered the attentions of the people to traditions, in ancient times, paper was mainly used for writing, packaging and pasting, however, with the rapid development of high technologies, especially the application of computers have greatly reduced the use of paper in daily life, and all kinds of painting papers have also caused the reduction of ancient papers use, and the ancient method papers that few people value are disappearing.

\section{2) Handicraftsmen stick to traditional concepts}

Interviews show that generally the handicraftsmen think little of combining with current market economy, in their opinions, the ancient method paper making should be accepted by the society, and nobody pays attention to innovation or reform of the paper making process and varieties. However, if having no process or renovation, any process will be rejected by the society, and those which are closely related to the society will continue.

\section{3) No industrialization or collectivization}

Seen from the history, the higher demand in Tang Dynasty brought higher economic benefits, so the paper making in Beizhang Village reached the peak time in Tang Dynasty. Yet after China's reform and opening up, the industrial development makes it unnecessary to make paper by hand, as a result the demand for handcraft paper was lower, which finally caused the lower economic benefits, finally the handcraft paper making are declining.

\section{Paper Making Process Flow int Beizhang Village}

\section{1) Raw materials for paper making}

Since the paper making technology was invented, ancient Chinese people selected plants of different kinds and from diverse regions as raw materials. The raw materials for paper making in Beizhang Village was paper mulberry, also called mulberry bark in Japan, which belongs to deciduous tree, high adaptation, growing fast, widely distributed, white color.

\section{2) Process flow}

According to the inheritor named Zhang Fengxue, the ancient paper process in Beizhang Village generally needs ten steps and seventy two sub-steps before completion. Main tools for the paper making include paper channel, paper splint, hammer, main process flows are given as follows:
I. Collection of raw materials: paper mulberry barks main materials for paper making, generally the barks are collected in spring and winter. The paper made of the barks collected in sprint looks black, so it is called black paper. The paper made of the barks collected in winter looks white, so it is called white paper. II. Peeling for immersion: peel the barks and cut into $70 \mathrm{~cm}$ long, dry then bind together and immerse in water for about 7 days to soften the barks. III. Steaming: Put the immersed barks in a pot, steam for over 12 hours to soften its fibers and remove sundries so as to withdraw fine fibers. IV. Grinding: put the steamed bark fibers under stone rollers for grinding to smash the fiber and make it separate from manoxylic wood. Then add whitewash to immerse several days to soften the coarse fiber remained in the barks, then take it out to ferment for a long time. V. Steaming and washing: steam the fermented fiber again, and after a night, put it into bags and wash by swaying in running water, then clean the coarse sundries and lime in the pulp. VI. Grinding and hammering: material processing is the heaviest step in the paper making, generally repeatedly rub the washed pulp with manpower, water driven hammer or stone roller and hammer into paste and make fiber sheets, called Fanzi. VII. Cutting and hammering: take special knife to cut up the fiber sheets, then place in stone mortars for repeated hammering with wood hammers to form floss-shaped fiber; VIII. Paper making: Take the hammered fiber and put them into proportioned pulp chest, mix with sticks unceasingly till forming final pulp, then put bamboo splint in the pulp and the fiber in the pulp will cover the splint uniformly, finally filter unnecessary water, an even thin fiber film will leave on the splint, which is called wet paper. IX. Pressing and drying: Squeeze needless water out of the wet paper for drying, after the wet paper is accumulated to a certain number, a tool can be used for pressing to squeeze the water. During the pressing, just keep slight, then tear the wet paper piece by piece and past it on walls for drying. X. Paper tearing: this the final step for traditional paper making, take down the paper piece by piece and put together, and one hundred pieces can be a unit.

\section{INHERITANCE AND INDUSTRIAL DEVELOPMENT AND HANDCRAFT PAPER MAKING IN OTHER REGIONS.}

Currently, there are still few remains of handicraft paper making in Tibet, Shanxi, Shandong, Henan, Yunnan and so on. In Tibet, the people take local Chinese Stellera Root as raw material to make paper in order for printing books; there are still few writing papers made from bamboo at Chengshi Village, Ehu Town, Qianshan County, Jiangxi Province and mulberry bark paper making at Zhifang Village, Qufu, Shandong Province; besides, there are over half of families which make stencil tissue paper at Mangtuan Village, Mengding Town, Gengma County, Yunnan Province, which is called "White Sand" by the Dai people, in the meantime, the village is building a tourism village and creating a tourism brand of the first village in paper making by the Dai people.

Take the Dongba paper as an example, the raw materials of the Naxi come from the local unique plants, in ancient, Dongba paper was used to write classics of Dongba faith, for 
it can be stored for a long time due to quality nature against worms. In recent years, with the development of tourism in Yunnan, Naxi culture has been introduced to the world relying on tourism products, of which, Dongba paper is used for more than classics, it is made into Naxi business cards, and the Naxi characters, totem and paintings are printed on Dongba paper, some are even made into tourism souvenirs such as lanterns.

\section{INDUSTRIALIZED DEVELOPMENT OF PAPER MAKING IN BEIZHANG VILLAGE, CHANG'AN}

Guided by the industrialized development, Beizhang Village may restore what it used to be and more people will inherit the process, it should go just like this.

\section{A. Diversity Development}

Currently the paper making in Beizhang Village basically adopts ancient method, the paper has light grey color without glue. Though an ancient method is adopted for paper making, yet it has lost the market share. Seen from the social demand, the paper is mainly used for painting or for general writing or freehand brush works. Yet for traditional Chinese realistic painting, though it is sound in color and character yet it has no glue or vitriol which will cause unexpected ink flow, thus it will lose the market. If glue and vitriol can be added to the final procedure of the paper, the paper will be used for traditional Chinese realistic painting, and its application scope is enlarged as well.

In addition, based on the tradition, more papers shall be developed with different colors through adding something such as leaves, fiber and so on, thus it will be popular in the people.

\section{B. Tourism and Souvenir Development}

Xi' an is a famous city which was ever capital of thirteen dynasties. Currently there hundreds of tourism resources developed here, and thousands and thousands of tourists and five hundred thousand international tourists visit in Xi' an each year. In order to develop the tourism resources, the handicraft paper making process in Beizhang Village can be made open, set up ancient paper museum or paper making museum in Beizhang Village to show the paper making, through the on-the-spot performance, the paper making process will be shown to tourists, and tourists may watch the paper making process and experience it, besides, other folks local can be developed as well in Shaanxi so as to increase the economic benefits of the whole village and even drive Chang'an District and the whole economic development in Xi'an.

The ancient method paper can be developed into souvenirs with Xi'an features, or the ancient paper can be made into notebooks; or the paper can be used as carriers for folk art such as paper-cut and shadow figures, etc. as such it can not only show the folk art but also promote the ancient paper here.

\section{Development of Painting Industry}

In ancient times, the ancient method paper was basically used for writing, which can be seen in the Annals of Chang'an County. Xi'an is the hometown of writing and painting which are the most distinct symbols of $\mathrm{Xi}$ ' an culture. Though most of current writing and painting adopt rice paper from Anhui, yet many collectors and painters at home abroad directly purchase paper at the handicraft workshops of Zhang Fengxue and so on due to the good hand feeling, high flexibility and long term color preservation and storage. The handcraft paper fully shows natural beauty and environmental protection, which are rare for calligraphers and painters, which may bring inspiration for creation, but the price is twice other papers. Beizhang Village shall be encouraged to develop new brand paper aiming at drawing and writing, relying on batches of production, the papers will be provided to artists, calligraphers and painters so as to create a top grade industrial brand.

\section{CONCLUSION}

Up to now, the technique and scale of handicraft paper making in China are still not compared by other countries, however, seen in the long run, the intangible cultural heritages are still disappearing, so we have to start quickly and protect and develop the handicraft paper making process through all kinds of rational measures. The inheritance and continuance of handicrafts shall need not only the support in spirit and material but also to be connected with the modern life in order for vitality and showing the value of traditional handicrafts in current society.

\section{REFERENCES}

[1] Rong Yuankai, Invention and Development of Paper Making Technology by Cai Lun [M]. Beijing: China Light Industry Press, 1994

[2] Lyu Pintian, Protection and Development in Production-Discussion on Productive Protection of Traditional Handicrafts [J] Art Observation, 2009

[3] Li Yuan, Investigation and Research on Traditional Paper Making Process in Beizhang Village, Shaanxi Province [D] 2009

[4] Li Xiaocen, Paper Making and Printing Technologies of Minorities in Yunnan [J]. China Historical Materials of Science and Technology, 1997. 